\section{WASHINGTON STATE UNIVERSITY}

\section{Boeing Chair in Advanced Materials}

and Director of the Center for Materials Research

\section{Position Description:}

The Boeing Chair in Advanced Materials is available, with tenure or tenure track, and will include instructional responsibilities as well as the responsibilities of the Director of the Center for Materials Research at Washington State University. The Center is a relatively new organization of faculty and students from the Departments of Chemistry, Mechanical and Materials Engineering, and Physics with active research interests in a number of areas in materials science and engineering, such as thin films, laser ablation, fracture, deformation, defects, surfaces, and simulation/modelling. The University intends to expand the scope and level of research being conducted by the Center. Therefore, the responsibilities of the Director will be to plan, develop, organize, and conduct research activities within the Center and to expand its funding base. The Boeing Chair and the Director's position will each be subject to review at the conclusion of an initial five-year term.

\section{Qualifications:}

An outstanding individual with a $\mathrm{PhD}$ in an appropriate field is sought with demonstrated levels of current excellence in research leadership, conduct of applied research, and attraction of funding in areas germane to the activities of the Center. The successful candidate will have joint appointments in the College of Engineering and Architecture and the College of Sciences.

\section{Inquiries and Applications:}

The effective start date is January 1, 1996. Inquiries may be directed to: Dr. Richard G. Hoagland, (509) 335-8280; Fax: (509) 335-4662, e-mail: hoagland@ honcho.mme.wsu.edu. To apply submit a detailed statement of interest, a C.V., and three professional references to: Mrs. Jan Danforth, Department of Mechanical and Materials Engineering; Washington State University; Pullman, WA 99164 2920. Review of applicants will begin September 1, 1995 and proceed until the position is filled.

Washington State University is an EO/AA educator and employer. Protected group members are encouraged to apply.

\section{UNIVERSITY OF MISSOURI-ROLLA Research Assistant Professor Position \\ A Research Assistant Professor Position} is available at the University of MissouriRolla, Graduate Center for Materials Research. Expertise and experience in electrometallurgical processes including winning, refining, anode development, mineral leaching, and corrosion is essential. Electrochemical characterization skills such as polarization, EIS, $X$ ray diffraction, and microscopy are necessary. Applicants must possess a PhD degree in metallurgy or electrochemistry. Postdoctoral experience in the areas described is important and excellent written and verbal communication skills with proven capabilities in proposal writing are a must. Application deadline: August 25, 1995. Send resume and names and telephone numbers of three references to:

Prof. Thomas J. O'Keefe

Graduate Center for

Materials Research

University of Missouri-Rolla

Rolla, MO 65401

UMR is an Equal Opportunity
Affirmative Action Employer.

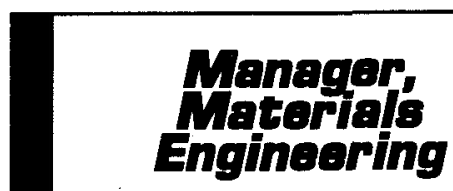

Copeland Corporation, the world's largest manufacfurer of compressors and condensing units for the air conditioning and refrigeration industries, is a leading billion dollar company with over 70 years of continued success. We are seeking a talented, hands-on individual for this opportunity at our headquarters facility in Sidney, Ohio (just north of Dayton).

The selected individual would be responsible for planning and directing all activities related to engineering support and R\&D functions of the Materials Deparment. Duties would also include the development of materials and process specifications, and performing $Q C$ analysis. Requirements tions, and performing $Q C$ analysis. Requirements
include an MS in Material Sciences or equivalent, and 10 years of experience with materials responsibility. Candidate must possess knowledge of metallurgy, chemistry, and state-of-the-art materials. Extensive experience in the use of conventional materials is also required.

We offer an excellent salary and benefits package including relocation assistance to our west central Ohio location which offers many small town amenities and close proximity to major metropolitan markets. For confidential consideration, submit your resume with salary requirements to: Professional Employment Dept-MC, COPELAND CORPORATION, P.O. BOX 669, Sidney, OH 45365-0669, FAX (513) 498-3887. Equal opportunity employer, $\mathrm{m} / \mathrm{/} / \mathrm{d} / \mathrm{v}$. Committed to worktorce diversity.

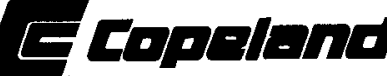

1995 AD CLOSING DEADLNE

August 1, 1995 for the September issue, Theme: Defects in Polymers TO PLACE YOUR AD, CALL

MARY E. KAUFOLD AT (412) 367-3036

\section{YALE UNIVERSITY}

Department of Mechanical Engineering

The Department of Mechanical Engineering is seeking one or more faculty members in the general areas of materials science and/or mechanics of solids at the level of assistant, term associate, or professor. Faculty members are expected to teach both undergraduate and graduate courses, develop course material, advise graduate students, and create a strong sponsored research program. Candidates should send a letter of interest with a detailed resume, a statement of teaching and research interests, copies of three principal publications (where appropriate), and names, addresses, and telephone numbers of three references to: Chair, Department of Mechanical Engineering; Yale University; P.O. Box 208284; New Haven, CT 06520 8284. Deadline for all applications: September 30, 1995.

Yale University is an equal opportunity employer.

\section{UNIVERSITY OF ILLINOIS AT URBANA-CHAMPAIGN Department of Materials Science and Engineering Faculty Positions}

The Department of Materials Science and Engineering at the University of Illinois at UrbanaChampaign invites applications for regular, full-time tenure-track and/or tenured faculty positions in the areas of bio-materials, ceramics, metals, and polymers. To be considered for a tenured position, the applicant must have recognized national and international stature. Applicants for junior positions are preferred and should have strong qualifications for teaching materials science and engineering at the undergraduate and graduate levels. Candidates will be expected to develop an outstanding research effort of their own in their field of choice, but strategic areas are favored. Successful candidates must have a distinguished record of accomplishment in one or more of the areas specified and will be expected to perform well in both teaching and research activities.

Applicants must hold an earned Doctorate in an appropriate field. Salary and rank will be commensurate with qualifications. The proposed starting date for each position is Fall $\mathbf{1 9 9 5}$ or later. All interested applicants are asked to provide a professional curriculum vitae including teaching experience, a list of publications, and an outline of a few pages describing their proposed program of research. Candidates for tenure-track positions should also request that three (3) letters of reference be sent directly to the department. Candidates for tenured positions should include the names, addresses, and telephone numbers of at least three (3) references. To ensure full consideration, applications must be received prior to October 15 , 1995. Intenviews may take place during the application period, but a final decision will not be made until after the deadline for applications.

Applications should be addressed to:

Chair, Faculty Search Committee, Department of Materials Science and Engineering

1304 W. Green Street, Urbana, Illinois 61801, Phone: 217-333-1440

The University of Illinois is an Affimative Action, Equal Opportunity Employer. 